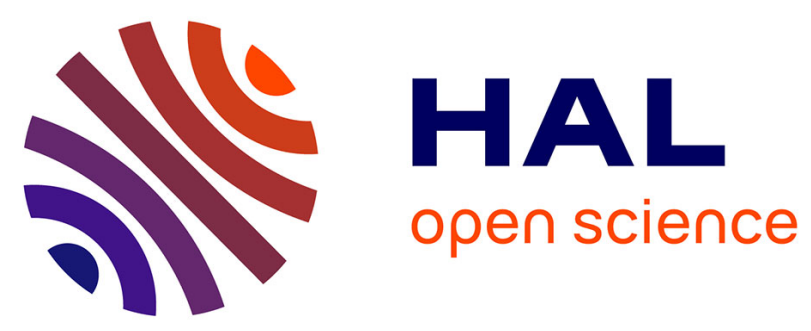

\title{
First Assemblies Using Deep Trench Termination Diodes
}

Fédia Baccar, Loïc Théolier, Stephane Azzopardi, François Le Henaff, Jean-Yves Delétage, Eric Woirgard

\section{To cite this version:}

Fédia Baccar, Loïc Théolier, Stephane Azzopardi, François Le Henaff, Jean-Yves Delétage, et al.. First Assemblies Using Deep Trench Termination Diodes. The 26th International Symposium on Power Semiconductor Devices and ICs (ISPSD'14), Jun 2014, Waikoloa, United States. pp.143-146, 10.1109/ISPSD.2014.6855996 . hal-01017522

\section{HAL Id: hal-01017522 \\ https://hal.science/hal-01017522}

Submitted on 2 Jul 2014

HAL is a multi-disciplinary open access archive for the deposit and dissemination of scientific research documents, whether they are published or not. The documents may come from teaching and research institutions in France or abroad, or from public or private research centers.
L'archive ouverte pluridisciplinaire HAL, est destinée au dépôt et à la diffusion de documents scientifiques de niveau recherche, publiés ou non, émanant des établissements d'enseignement et de recherche français ou étrangers, des laboratoires publics ou privés. 


\title{
First Assemblies Using Deep Trench Termination Diodes
}

\author{
F. Baccar, L. Théolier, S. Azzopardi, F. Le Henaff, J.-Y. Deletage, E. Woirgard \\ University of Bordeaux, Bordeaux Institute of Technology, IMS Laboratory \\ CNRS UMR 5218, F-33400 \\ Talence, France \\ e-mail: fedia.baccar@ims-bordeaux.fr
}

\begin{abstract}
In this paper, diodes manufactured in 2008, allowing to obtain the first electrical measurements of the Deep Trench Termination $\left(\mathrm{DT}^{2}\right)$, are analyzed in a reliability purpose. For the first time, assemblies are made using DT $^{2}$ diodes reported on Direct Bonded Copper (DBC) substrates using silver sintering process in order to confirm the possibility to integrate this technology in future lead-free packaging. Indeed, geometric singularities and different mechanical properties of BenzoCycloButen (BCB) and silicon could weaken the chip. In order to confirm the device electrical stability, passive thermal ageing are achieved. Then, breakdown voltage measurements, optical observations and TCAD-SENTAURUS simulations are investigated in order to provide explanation of the induced phenomenon linked to the aging.
\end{abstract}

\section{INTRODUCTION}

The breakdown voltage of high-voltage power semiconductor devices is one of the most important features. As a consequence, to improve the breakdown voltage, it is necessary to create an adequate edge termination to reduce the electric field peak at the device periphery [1].

Many studies have proposed several techniques to practical chip design in improving the breakdown voltage under the planar technology, for example junction termination extension (JTE) [2], field plate [3], semi insulating polycrystalline silicon (SIPOS) [4]. Despite the advantage of these techniques, they consume a large surface area for high voltage devices.

Recently deep trench structure has become one of the design options for semiconductor devices. The Deep Trench Termination $\left(\mathrm{DT}^{2}\right)$ has a possibility to drastically reduce the termination area comparing to the above conventional structure.

The $\mathrm{DT}^{2}$ was presented in 2009 [5] and then, several studies have proposed electrical improvements. Seto et al. [6] emphasized the relationship between the trench depth and the termination length for optimum design with the required termination length and/or trench depth. Kamibaba et al. [7] pointed out that positive charges due to the holes accumulated in the trench side wall effectively terminate the high electric field in chip edge region, which is the key mechanism for the edge termination design with deep trench structure.

Other studies demonstrate the possibility to use BCB passivation layers in Wafer Level Chip Scale Package (WLCSP) process [8] or use it in order to create moisture sensor [9].

The aim of this work is to study the reliability of a 1200 Volts Deep Trench Termination in order to confirm the possibility to integrate this technology in future lead free packaging. This paper presents in a first part, the first assemblies using $\mathrm{DT}^{2}$ : The diode was reported on $\mathrm{DBC}$ substrates using silver sintering process in order to confirm the presence of trenches do not weaken the mechanical strength of the chip. In a second part, passive thermal ageing are achieved in order to characterize the stability of the electrical behavior of the diodes. For this, reverse characteristics measurements and TCAD SENATURUS simulations are investigated.

\section{DEEP TRENCH TERMINATION CONCEPT}

The schematic of a 1200 Volts diode structure is presented in Figure 1. This new junction termination, called the deep trench termination is based on a large and deep trench filled by a dielectric, associated to a field plate.

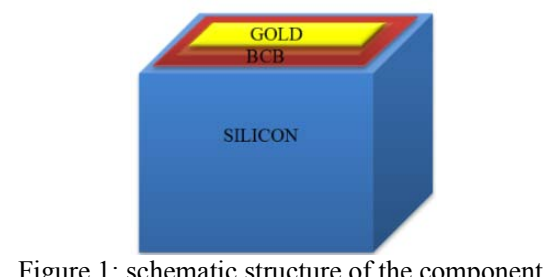

Figure 2 shows the $3 \mathrm{D}$ cross section structure of the component.

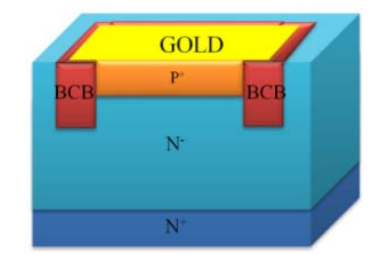

Figure 2: 3D cross section of the $\mathrm{DT}^{2}$.

This work was supported by the French National Research Agency (ANR) through SUPERSWITCH program (ANR 2011 BS09 033) and the Aerospace Valley competitiveness cluster. 
The diode is composed by a $10^{14} \mathrm{~cm}^{-3} \mathrm{~N}^{-}$concentrations substrate with a $\mathrm{P}^{+}$implantation in top layer and a $\mathrm{N}^{+}$ implantation in the bottom layer. A deep trench $(105 \mu \mathrm{m} x$ $75 \mu \mathrm{m})$ is filled by BCB in order to realize the termination. A field plate is needed to draw out the electrostatic potential in the trench.

\section{SINTERING PROCESS}

\section{A. Silver Sintering process presentation}

Sintering pastes have been developed for die attach applications. Silver is used as the base material, as it is simple to process and it offers very high thermal and electrical performance [10].

Silver sintering die attach is a promising technology for high temperature power electronics lead-free packaging. Indeed, the increase in operating temperature requires new soldering alloys with even higher melting points. Silver sintering, on the contrary, is a solution which only requires moderate $\left(<300^{\circ} \mathrm{C}\right)$ process temperature [11].

The die attach process can be summarized in three steps (Figure 3). In a first step, the sliver paste is spread on the substrate with a silk screen printing to ensure a uniform deposit thickness. The debinding step is required to remove the binding additives as a prerequisite for sintering. Finally, sintering, which is the step of densification where particles are getting bigger and the number of internal voids decreases.

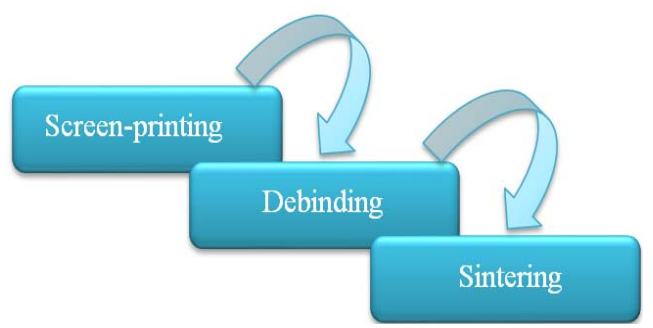

Figure 3: die attach process.

\section{B. Experimental approach}

For silver sintered assemblies silver paste (Argomax ${ }^{\circledR}$ 2020) has been deposited on the surfaces by screen printing.

Deposit was dried and sintering was processed under low pressure (10MPa) using Instron press equipped with two heating platens (Figure 4). This apparatus can apply forces ranging from $60 \mathrm{~N}$ up to $30 \mathrm{kN}$.

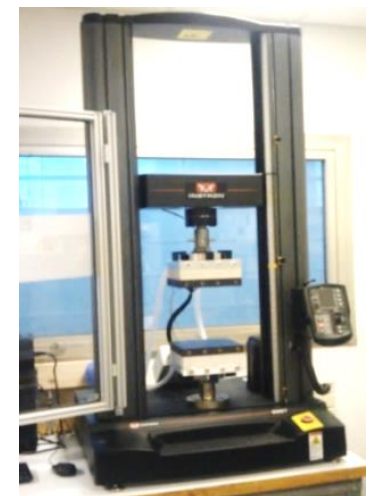

Figure 4: Press for sintering equipped with tow heating platens.
Die-attach module was made using a DBC substrate with gold metal substrate finishes $(\mathrm{Cu} / \mathrm{Ni} / \mathrm{Au})$. The test vehicles are presented in Figure 5, the diodes has been sintered on the substrate.

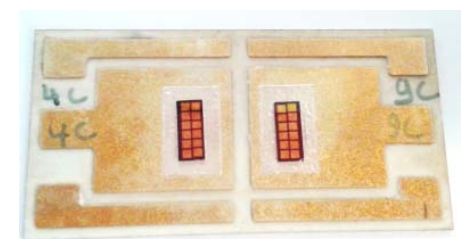

Figure 5: test vehicle after silver sintering.

The first assemblies using silver sintering process were realized and a cross-section has been made (Figure 6).

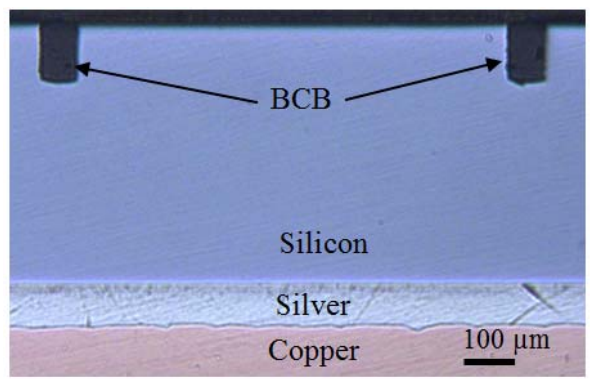

Figure 6: Cross-sectional view of the die attach after silver sintering.

Study of cross-sections shows that silver sintered dieattaches are homogeneous with regular thickness all along the joint and no void can be observed. Furthermore, the diode presents none crack around the trenches termination that confirms the trenches do not restrict assembly solutions with pressure and high temperature.

\section{Electrical reverse Characteristics of the DT $T^{2}$ after sintering}

Just after sintering, electrical reverse characteristics were performed with the aim at verifying that the sintering process did not effect on the electrical characteristics, and to confirm that a 4-year storage in clean room did not degrade this electrical parameter. Figure 7 presents the two main behaviors measured. The first is named "Diode 1" with a low leakage current and the second is named "Diode 2" with a higher leakage current.

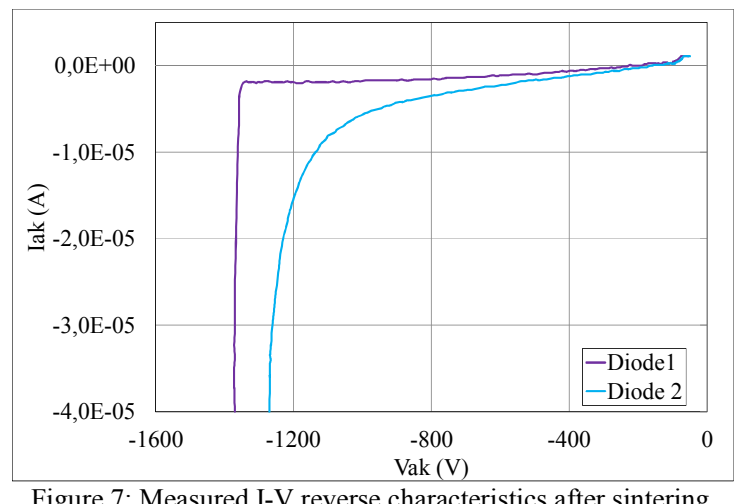

Figure 7: Measured I-V reverse characteristics after sintering.

The $\mathrm{DT}^{2}$ breakdown voltage keeps a value above $1200 \mathrm{~V}$ after sintering. The reverse characteristics are recorded in 
order to keep it as reference, and to compare with characteristics after thermal ageing.

\section{THERMAL AGEING}

During the lifetime a component is exposed to passive temperature swings coming from the environment and active temperature cycles generated by self-heating under operation. Temperature cycling and power cycling tests represent these conditions. Then, to simulate the real application, passive power cycling tests are most commonly used in the qualification procedure for component.

\section{A. Experimental approach}

A climatic chamber with two independent rooms has been used. Temperature has been set up to two specific values. In this study, standard temperature profile has been set up: a high temperature value of $+125^{\circ} \mathrm{C}$ and a low temperature of $-40^{\circ} \mathrm{C}$ are fixed as depicted in Figure 8.

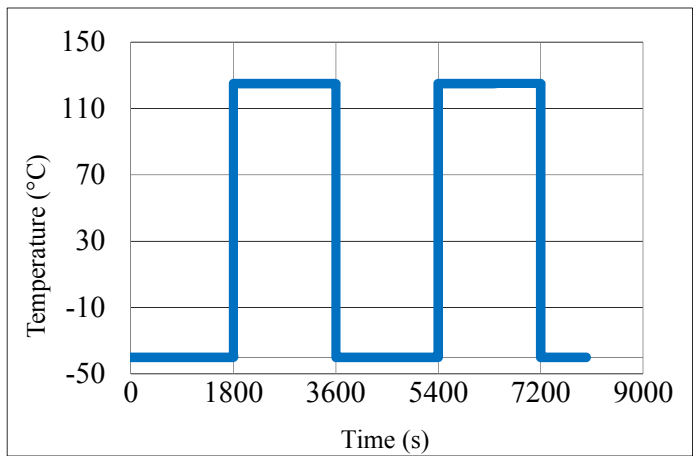

Figure 8: Thermal ageing profile.

\section{B. Results}

Every 50 thermal cycles, the thermal cycling is stopped and the I-V reverse characteristics were achieved. Figure 9 exhibits the reverse characteristics after thermal ageing for the diodes 1. An increase of the breakdown voltage can be observed for such diodes. The diodes 1 still present excellent behavior after 400 hours thermal cycling with a breakdown voltage near $1600 \mathrm{~V}$.

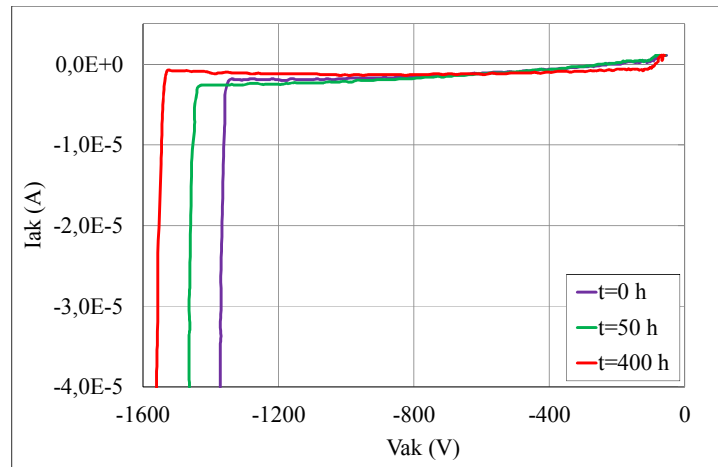

Figure 9: Measured I-V reverse characteristics after thermal ageing for diodes 1 .

An assumption on this variation can be proposed: positive electric charges are stored in the $\mathrm{Si} / \mathrm{BCB}$ interface and create a virtual $\mathrm{P}^{+} / \mathrm{N}^{-}$junction along the trench. However, no experimental observation has been made.

Figure 10 exhibits the reverse characteristics for the diodes 2 . A decrease of the breakdown voltage with a decrease of the leakage current can be observed for such diodes. The diodes 2 still present excellent behavior after 400 hours thermal cycling but with a breakdown voltage near $900 \mathrm{~V}$.

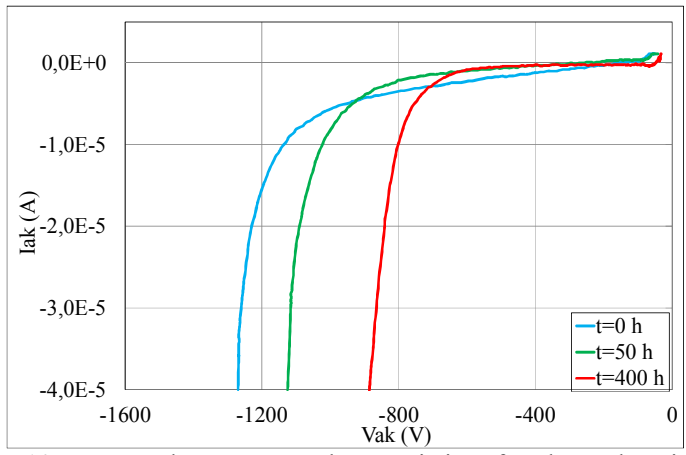

Figure 10: Measured I-V reverse characteristics after thermal ageing for diodes 2 .

Optical observations do not highlight that a peeling of the resin and silicon can explain these variations. Like for the diodes 1 , a hypothesis of this variation is that negative electric charges are stored in the $\mathrm{Si} / \mathrm{BCB}$ interface, creating a virtual $\mathrm{N}^{+} / \mathrm{N}^{-}$junction along the trench. Therefore, finite elements simulations were carried out.

\section{2D FINITE ELEMENT SIMULATION}

In multi-material devices, thermal variations induce a mechanical stress; so it is possible that a separation of materials along the $\mathrm{Si} / \mathrm{BCB}$ interface and fixed charges appear.

At the $\mathrm{Si} / \mathrm{BCB}$ interface, more precisely in internal interface of the termination and external interface of the termination, a void with different width has been created to observe its impact on the reverse characteristics (Figure 11).

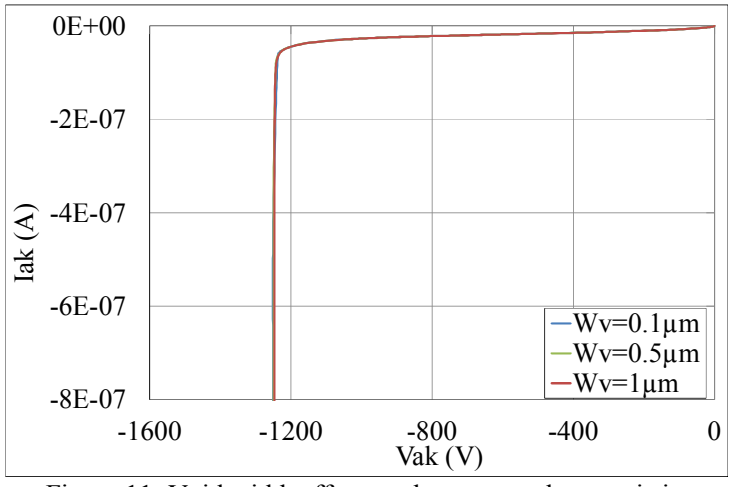

Figure 11: Void width effect on the reverse characteristic.

The results exhibit that a separation at the interface does not affect the breakdown voltage. This is explained by the fact that the electric field is concentrated at the end of the field plate, like presented in many papers ([1], [7]) and a void insertion does not disturb the electric filed in this region. 
Another type of degradation of the simulated structure is the insertion of fixed charge in the $\mathrm{Si} / \mathrm{BCB}$ interface. Figure 12 illustrates the $\mathrm{I}-\mathrm{V}$ reverse characteristics with different $\mathrm{Si} / \mathrm{BCB}$ interface charges.

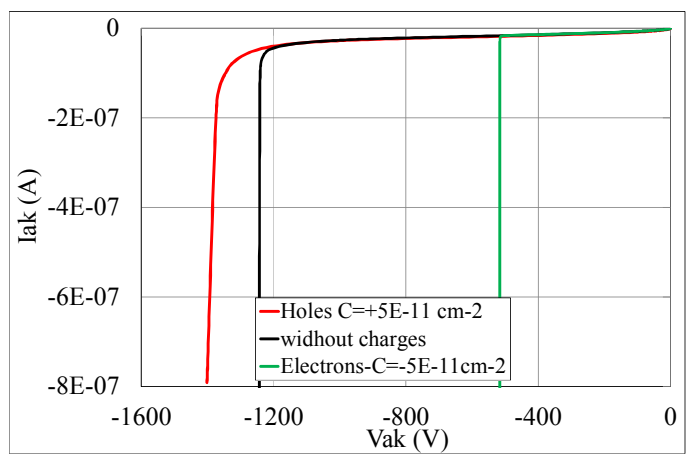

Figure 12 : Fixed charges influence at the $\mathrm{Si} / \mathrm{BCB}$ interface on the reverse characteristics.

The breakdown voltage is modified by charges insertion at the $\mathrm{Si} / \mathrm{BCB}$ interface. The simulation confirms the device is sensitive to fixed charges and confirms the hypothesis. Nevertheless, the simulation does not explain why the diodes 1 store negatives electric charges and the diodes 2 store positives electric charges.

\section{CONCLUSION}

The diodes manufactured 4-years ago have been reported on DBC substrates using silver sintering process. The fear that the trenches terminations cause cracks during sintering has been rule out. This has confirmed that this technology can be integrated in future lead-free packaging. Furthermore, first reliability tests have been achieved. Two behaviors on the breakdown voltage evolution under accelerated ageing are observed. These evolutions can be explained by fixed charges insertion at the $\mathrm{Si} / \mathrm{BCB}$ interface but more investigations need to be carried out in order to explain why some diodes store positives charges and other negatives charges.

\section{REFERENCES}

[1] L. Théolier, H. Mahfoz-kotb, K. Isoird, and F. Morancho, "A new junction termination using a deep trench filled with benocyclobutene", IEEE Trans. Electron Devices, vol. A30, pp. 687-689, June 2009.

[2] V. A. K. Temple, and W. "Junction termination extension for the near ideal breakdown voltage in p-n junction", IEEE Electron Device Letters, vol ED-33, no. 10, pp.1601-1608, Oct. 1986.

[3] C. B. Goud, K. N. Bhat, "Two-dimensional analysis and design consideration of high-voltage planar junctions equipped with field plate and guard ring", IEEE Trans. Electron Devices, vol. 38, pp. 1497-1504, Sept. 1991.

[4] D. Jaume, G. Charitat, J.M. Reynès, P. Rossel, "High voltage planar devices using field plate and semi-resistive layers", IEEE Trans. Electron Devices, vol. 38, pp. 1681-1684, July 1991.

[5] L. Théolier, H. Mahfoz-kotb, K. Isoird, and F. Morancho, "A new junction technique: the Deep Trench Termination $\left(\mathrm{DT}^{2}\right)$," ISPSD 2009, pp. 176-179, 2009.

[6] K. Seto, R. Kamibaba, M. Tsukuda, and I. Omura, "Universal trench edge termination design,” ISPSD 2012, pp. 161-164, 2012.

[7] R. Kamibaba, K. Takahama, and I. Omura, "Design of trench termination for High Voltage Device," ISPSD 2010, pp. 107-110, 2010.

[8] K.O. Lee, Jin Yu, J.Y. Kim, and I.S. Parck, "Thermo-Mechanical Reliability of the Benzocyclebuten (BCB) film in a WLCSP process", EMAP 2001, pp 84-87, 2001.

[9] A. Tetelin, A. Achen, V. Pouget, C. Pellet, M. Töpper, and J.L. Lachaud, "Water solubility and diffusivity in BCB resins used in microelectronics packaging and sensor applications," IMTC 2005, pp. 792-796, 2005.

[10] A.Masson, C. Buttay, H. Morel, C. Raynaud, S. Hascoet, and L. Greamillard,"High-temerature die attaches for $\mathrm{SiC}$ power devices," EPE 2011.

[11] F. Le Henaff, S. Azzopardi, J.Y. Deletage, E. Woirgard, S. Bontemps, and J. Jouget, "A preliminary study on the thermal and mechanical performances of sintered nano-scale silver die-attach technology depending on the substrate metallization", Microelectronics Relability 2012 , vol. 52, pp. 2321-2325. 